\title{
FORMAÇÁO DOS PRÓPRIOS EDUCADORES: UM PRINCÍPIO EDUCATIVO DO Movimento dos TrabalHadores Rurais Sem Terra (MST)
}

\author{
OWN EDUCATORS TRAINING: AN EDUCATIONAL PRINCIPLE OF \\ Movimento dos Trabalhadores Rurais Sem Terra (MST)
}

\begin{abstract}
Cláudio Rodrigues da Silva Doutorado em Educação pela Universidade Estadual Paulista (Unesp) - Marília - São Paulo - Brasil Orcid: http://orcid.org/0000-0001-9036-3101 silvanegrao@gmail.com

Neusa Maria Dal Ri Livre-Docente III - Universidade Estadual Paulista (Unesp) - Marília - São Paulo - Brasil Orcid: http://orcid.org/0000-0002-3000-2280

neusamdr@terra.com.br
\end{abstract}

Resumo: Este texto aborda a formação de educadores do Movimento dos Trabalhadores Rurais Sem Terra (MST) e tem como principal objetivo demonstrar que a formação dos próprios educadores é um princípio educativo essencial do projeto educacional desse Movimento. Articulada a outros princípios, a formação dos próprios educadores é fundamental para a educação dos Sem Terra, em conformidade com a pedagogia e as diretrizes político-econômicas do MST, que tem registrado avanços importantes nesse quesito recorrente na história da educaçáo e presente em iniciativas teórico-práticas de diferentes movimentos sociais de trabalhadores desde o século XIX. Esta investigação está integrada a projeto mais amplo e foi efetuada a partir de pesquisa bibliográfica e documental. Os procedimentos realizados foram o levantamento, seleção e leitura de obras e textos relativos à temática e de documentos publicados pelo MST. Após, operouse a sistematização e interpretação dos dados coletados.

Palavras-chave: Autoeducação. Educação em Movimentos Sociais. Educação e Trabalho. Formação de Professores. MST.

Aвstract: This text addresses the educators training topic. Its main goal is to demonstrate that the own educators training is an essential educational principle of the educational project of Movimento dos Trabalhadores Rurais Sem Terra (MST). Combined with other principles, the own educators training is fundamental for the education of the Sem Terra, according to the pedagogy and the political, and economic MST guidelines. The MST has moved forward in this issue, recurrent in the history of education and existing in theoretical-practical initiatives from different workers social 
movements as of the XIX century. This investigation is integrated into a larger project and was carried out based on bibliographic and documentary research. The procedures performed were the retrieval, selection and reading of works and texts related to the topic and documents published by the MST. Afterwards, the collected data were systematised and interpreted.

Keywords: Self-Education. Education in Social Movement. Education and Work. Teachers Training. MST.

\section{Introdução}

No presente artigo, aborda-se a temática da formação de educadores no Movimento dos Trabalhadores Rurais Sem Terra (MST). A problemática apresentada é parte dos resultados de pesquisa documental, bibliográfica e empírica que propóe um estudo de movimentos sociais de trabalhadores do século XIX, tais como o cartismo britânico, o anarquismo, o socialismo utópico e o marxismo, realizando um cotejamento com movimentos sociais atuais: MST e o Movimento Zapatista, que visa determinar proposiçóes comuns e transcendentes nas propostas educacionais desses movimentos.

Com base em Dal Ri (2012, 2013), a hipótese principal sustentada nesta pesquisa é de que esses movimentos têm princípios educativos comuns $^{1}$, quais sejam: a) elaboração e implantação de um projeto próprio de educação; b) crítica e/ou negação do ensino oficial estatal; c) implantação da gestão democrática nas escolas dos movimentos; d) formação dos próprios educadores; e) articulação entre ensino e trabalho produtivo.

Neste texto, tem-se por objetivo discutir e analisar o princípio da formação dos próprios educadores observado na pedagogia do MST. A hipótese subsidiária é de que o MST consegue avanços significativos na formação de educadores, tanto em perspectivas conservadoras quanto em perspectivas críticas ao sistema do capital e que visam transformaçóes sociais estruturais, como é o caso dos movimentos sociais de trabalhadores enunciados, que conceberam e implantaram projetos educacionais próprios.

A educação em movimentos sociais tem sido uma temática candente na área científica $(\mathrm{GOHN}, 2011)$, gerando pesquisas que envolvem variadas perspectivas político-ideológicas ou teórico-metodológicas. A questão da formação de professores é uma temática polêmica e recorrente na his- 
tória da educação (MANACORDA, 1992; SAVIANI, 2009; TANURI, 2000), haja vista o seu caráter estratégico para a consecução de projetos educacionais ou societários.

O MST é um objeto relevante de estudo, pois é um dos principais movimentos sociais de trabalhadores do Brasil e da América Latina, com repercussão e reconhecimento nos âmbitos nacional e internacional, destacando-se pelas suas iniciativas na área da educação formal e não formal. (BAUER, 2009; DAL RI, 2015; MENEZES NETO, 2014)

Trata-se, aqui, de pesquisa documental e bibliográfica (SEVERINO, 2007; TRIVIÑOS, 1987) que adotou como procedimentos básicos o levantamento bibliográfico e documental, seguido de leitura, análise e interpretação da literatura acadêmica (artigos, livros, teses e dissertaçóes) e de documentos relacionados às temáticas envolvidas neste estudo. Foram utilizados preferencialmente documentos oficiais do MST, assim como textos de seus principais intelectuais orgânicos e de autores que pesquisam o Movimento e a temática indicada.

\section{Notas sobre a educação do MST}

Fundado em 1984, o MST tem como objetivo principal a organização dos trabalhadores na luta em prol da reforma agrária no Brasil e resulta de um processo de gestação que contou com o aporte de movimentos e lutas sociais anteriores. Segundo o MST (2019), no final da década de 1970, quando as contradiçóes do modelo agrícola se tornaram mais intensas, ressurgiram as ocupaçôes de terra.

A conjuntura de fundação do MST foi marcada pela efervescência de lutas sociais levadas a termo por diferentes movimentos populares, sendo que vários deles demandavam distintos direitos - como educação escolar -, em um país que, historicamente, vetou ou restringiu, de diversas formas, o acesso da ampla maioria da classe trabalhadora, em especial daquelas fraçóes mais precarizadas, à educação escolar. Há que se considerar que, em sociedades grafocêntricas, os conhecimentos escolares são elementares para o exercício de determinados direitos. Além disso, a educação escolar potencializa as possibilidades de acesso ou de apropriação de di- 
ferentes conhecimentos socialmente produzidos, configurando-se, assim, como fator de humanização.

No caso do MST, a luta pela educação está ligada à luta por diferentes direitos nas esferas da política, da economia e da cultura. Aliás, constitui parte significativa de sua história a luta por uma educação ampla, em contraposição à unilateralidade que tende a marcar a educação oficial propiciada pelo Estado a amplos setores da classe trabalhadora. É numa conjuntura de restrição ou negação de diversos direitos que o MST surge e passa a lutar, articuladamente, por terra e educação, entre outros quesitos (SILVA, 2014). É assim que, articulada e simultaneamente à luta pela terra, também luta pela democratização da educação, pois ambas são, desde a gênese do Movimento, elementos fundamentais e indispensáveis para seu projeto político: "A relação do MST com a educação é, pois, uma relação de origem: a história do MST é a história de uma grande obra educativa." (MST, 1999, p. 5)

O MST tem um projeto educativo próprio, cujos princípios filosóficos e pedagógicos são consoantes com seus objetivos, ideologia e concepção de mundo. Ele está presente em 24 estados brasileiros e atua em todos os níveis e em diferentes modalidades do ensino formal, seja por intermédio de iniciativas próprias, seja por meio de convênios, além de desenvolver diversas iniciativas de educação não formal. Conforme o MST (2010; 2016, p. 1), há

mais de 2 mil escolas públicas construídas em acampamentos e assentamentos [...] 200 mil crianças, adolescentes, jovens e adultos com acesso à educação garantida [...] 50 mil adultos alfabetizados [...] 2 mil estudantes em cursos técnicos e superiores [...] mais de 100 cursos de graduação em parceria com universidades públicas por todo o país.

Os princípios filosóficos do Movimento (1996) são: educação para a transformação social; educação para o trabalho e a cooperação; educação voltada para as várias dimensóes da pessoa humana; e educação com base em valores humanistas e socialistas.

O MST tem uma pedagogia própria, denominada Pedagogia do Movimento (MST, 1999), cujos princípios são: relação entre prática e teo- 
ria; combinação metodológica entre processos de ensino e de capacitação; realidade como base da produçấo do conhecimento; conteúdos formativos socialmente úteis; educação para o trabalho e pelo trabalho; vínculo orgânico entre processos educativos e processos políticos; vínculo orgânico entre processos educativos e processos econômicos; vínculo orgânico entre educação e cultura; gestão democrática; auto-organização dos/das estudantes; criação de coletivos pedagógicos e formação permanente dos educadores/das educadoras; atitude e habilidades de pesquisa; combinação entre os processos pedagógicos coletivos e individuais. (MST, 1996)

A Pedagogia do Movimento é composta de várias pedagogias, dentre as quais se destacam: Pedagogia da Luta Social, Pedagogia da Organização Coletiva, Pedagogia da Terra, Pedagogia do Trabalho e da Produção, Pedagogia da Cultura, Pedagogia da Escolha, Pedagogia da História e Pedagogia da Alternância (MST, 1996). O MST tem valores que embasam a sua pedagogia, entre os principais, segundo documentos do próprio Movimento, estão a indignação diante das injustiças e da perda da dignidade humana, o companheirismo e a solidariedade, a igualdade combinada com o respeito às diferenças, à justiça e à democracia. (MST, 1996; 1999; 2001)

\section{O MST e a questáo da formação dos seus educadores}

O MST adota iniciativas para formar seus próprios educadores (CALDART, 1997; CAMINI, 1998; DAL RI; VIEITEZ, 2008). Dal Ri (2012) ressalta que a formação dos educadores do MST ocorre em conformidade com o seu projeto político. As primeiras açôes formais visando formar seus educadores datam do final da década de 1980, com a criação do Setor de Educação (CALDART, 1997; MST, 1996; 1999; 2001). Pelo fato de atuar em diferentes níveis e modalidades de ensino, o Movimento possui várias frentes de formação. No decorrer de sua história, diversas iniciativas visando a formação dos próprios educadores foram adotadas, como a criação do Curso de Magistério em escola própria e, mais recentemente, a celebração de convênios com universidades públicas para a cria- 
ção e realização dos cursos de Pedagogia da Terra. (DAL RI; VIEITEZ, 2008, ITERRA, 1997; MST, 1996; 1999; 2001; 2010; 2016)

A formação de educadores é um ponto fulcral do projeto educativo dos Sem Terra, quesito necessário para que os educadores tenham condiçóes de ensinar em conformidade com a Pedagogia do Movimento (DAL RI; VIEITEZ, 2008). Formar os próprios intelectuais orgânicos, em especial seus educadores, é um fator elementar para a consecução de projetos educativos ou societários. Conforme Stedile e Fernandes (2001, p. 42-43), "Nunca terá futuro a organização social que não formar os seus próprios quadros. Ninguém de fora da organização vai formar quadros para nós. Precisamos de quadros técnicos, políticos, organizadores, profissionais de todas as áreas."

Para ser educador do Movimento é necessário um conjunto de atributos imbricados entre si. Recorrendo a expressôes do MST (2001), são eles: ser do Movimento; ser sempre um educando; reconhecer-se como sem terra; ter o Movimento como referência; saber-se um educador do povo; ver os educandos como seres humanos; ser exemplo da prática de valores que libertam; estudar muito; aprender a educar pela coletividade; saber construir o ambiente educativo; e fazer a escola do povo sem terra. Para o MST (1996, 1999, 2001), o educador deve ser referência para o educando, o que demanda postura condizente, em todos os sentidos, com a Pedagogia do Movimento:

Para por em prática a pedagogia e a proposta de escola que estamos discutindo é preciso, mais do que tudo, de uma postura pedagógica de fundo, um jeito de ser educador, que compartilhe com os valores produzidos nesta história de formação humana que é a história dos Sem Terra, e que se abra ao movimento como princípio educativo, também de si mesmo. Que cuide e se deixe cuidar pelo Movimento, ajudando a fazer da pedagogia de quem ocupa a terra, uma arte de lavrar a vida e produzir gente. (MST, 2001, p. 31)

A função de educador requer articulação entre teoria e prática em termos técnico-científicos e político-ideológicos, isto é, de identidade, compromisso e organicidade com a política e as diretrizes do Movimento 
(CALDART, 1997; MST, 1996; 1999; 2001). Segundo o MST (1996, p. 8), "[...] educadores que não conhecem a realidade (seja a próxima, seja a distante), não têm como desenvolver um ensino que a tenha como base! [...] quem vive num assentamento não necessariamente conhece a sua realidade.” Em consonância com o princípio da gestão democrática, a indicaçâo e o aval das comunidades de origem, assentamentos e acampamentos são elementos determinantes para a escolha das pessoas que participarão dos cursos de formação de educadores. A expectativa é de que as pessoas indicadas ou selecionadas para a realização desses cursos, depois de formadas, retornem a suas comunidades para apoiá-las, trabalhando nos cursos e escolas do MST $^{2}$. (CALDART, 1997, DAL RI; VIEITEZ, 2008, STEDILE; FERNANDES, 2001)

A necessidade de formar os próprios educadores deve-se ao fato de que essa atividade precisa estar em estreita consonância com os princípios do Movimento, pois os educadores, a rigor, são os principais responsáveis, especialmente pela operacionalização do currículo nas dimensôes políticoideológica e técnico-científica, dimensões essas, em última análise, imbricadas. Historicamente, as classes dominantes, por intermédio do aparelho de Estado, em especial da escola, impóem restriçôes técnico-científicas, ideológicas ou morais para o ingresso ou atuação na docência oficial, como se pode constatar a partir, por exemplo, de Vicentini e Lugli (2009).

Por um lado, movimentos sociais de trabalhadores como os mencionados no início deste texto historicamente se empenharam para garantir o acesso e a apropriação dos conhecimentos técnico-científicos pelos seus integrantes. A cultura autodidata, a valorização dos estudos técnico-científicos e a autoeducação eram atividades recorrentes entre setores da classe trabalhadora (ENGELS, 2008, THOMPSON, 1987a). Desse modo, formar seus próprios educadores e ter suas próprias escolas foram práticas instauradas por alguns desses movimentos ainda no século XIX (DAL RI, 2012, SILVA, 2014). Por outro lado, as classes proprietárias, enquanto e o quanto puderam, negaram ou restringiram o acesso dos trabalhadores aos conhecimentos técnico-científicos, sendo oferecida a amplas parcelas das classes trabalhadoras uma educação baseada predominantemente na superstição, na moral e na ideologia das classes dominantes (BASBAUM, 1982; ENGELS, 2008; PONCE, 1981; THOMPSON, 1987b). E, mesmo quando os conhecimentos escolares ou os conhecimentos técnico-científi- 
cos passaram a ser necessários, principalmente para a formação da força de trabalho, são propiciados apenas seus rudimentos, em conformidade com a posição a ser ocupada pelos trabalhadores no processo produtivo. (BASBAUM, 1982; DAL RI; VIEITEZ, 2008)

A precariedade, em diversos sentidos, do ensino oficial afeta também a formação de professores, como se pode inferir a partir de Gatti (2010) e pela observação da atual precarizaçáo da escola pública. No entanto, esse fato não é algo recente ou inerente à atualidade. Dados apresentados por Engels (2008) e por Marx (1985) ilustram a precariedade das escolas de fábrica ${ }^{3}$, que não tinham condições elementares para desenvolvimento adequado do trabalho educativo, por exemplo, dada a incapacidade de o professor escrever corretamente o próprio nome.

Todavia, é importante reiterar que as restriçóes ao acesso e à apropriação dos conhecimentos técnico-científicos, ou dos conhecimentos escolares, por parte da classe trabalhadora não se devem ao histórico e recorrente argumento, tornado quase senso comum, de que por intermédio unicamente da educação sejam realizadas transformaçóes sociais estruturais. Entretanto, se por um lado os conhecimentos técnico-científicos não são uma espécie de panaceia, por outro também não são inócuos, pois eles têm implicaçôes, diretas ou indiretas, com a manutenção do consenso social, com a composição orgânica do capital, com a divisão social hierárquico-vertical do trabalho, com a meritocracia, entre outros fatores fundamentais para a reprodução da atual formação econômico-social. Além disso, há que se considerar que a educação escolar demanda recursos financeiros para sua execução, recursos esses disputados entre classes sociais e também entre suas frações.

O MST defende e reivindica a escola pública para todos. No entanto, ao mesmo tempo tece críticas ao ensino oficial porque, independentemente das contradiçóes, a prática principal do ensino estatal é, em última instância, $o$ atendimento às demandas de reprodução material e ideológica do atual modo de produção, cuja superação é defendida pelo Movimento. Para o MST (2001, p. 30),

Há algum tempo a escola deixou de se ver como lugar de formação humana. Não é sobre isso que a maioria dos professores têm discutido. Se a escola voltar a se preocupar com a formação 
humana, passará a prestar mais atenção nos sujeitos que a ocupam e dialogando com eles se dará conta de como pode ajudálos como pessoas, como sujeitos sociais.

As críticas do MST ao ensino oficial envolvem o currículo em sua totalidade, isto é, abrange tanto o currículo formal quanto o oculto, e entende que conteúdo e forma estáo imbricados. Coerentemente com a sua pedagogia, preza pela articulação entre teoria e prática, visando a formação para e no coletivo, na e para a militância política, o que não implica desconsiderar a dimensão técnico-científica. Assim, as matrizes pedagógicas do MST têm que perpassar, na teoria e na prática, todas as suas iniciativas educacionais, especialmente nos cursos de formação de educadores (CALDART, 1997; MST, 1996; 1999; 2001). O Movimento não compactua com o entendimento de que na escola não há espaço para a prática, apenas para a teoria:

Queremos que a prática social dos/das estudantes seja a base do seu processo formativo, seja a matéria prima e o destino da educação que fazemos. Queremos que o próprio curso seja lugar privilegiado de práticas, e que o estudo e a elaboração teórica sejam considerados práticas [...] (MST, 1996, p. 10-11)

Sem preterir a dimensão teórica, parte significativa da formação dos educadores do MST ocorre na vivência e na participação, de forma orgânica, nas relaçôes sociais cotidianas do Movimento, que é a grande e principal escola dos Sem Terra, inclusive dos seus próprios educadores (MST, 1996, 1999, 2001). Considerando-se que, a rigor, as instituiçóes oficiais formadoras de professores, por força da legislação (BRASIL, 1988, 1996) e por posicionamento político-ideológico de seus proprietários ou mantenedores, ainda que haja alguma margem de autonomia ou de resistência, têm que operar na lógica hegemônica, pode-se inferir que a ampla maioria dos professores do ensino oficial foi/é formada nos moldes hegemônicos, ou seja, na perspectiva do capital, sistema ao qual o MST tece críticas e propóe superar. (SILVA, 2014)Em cursos oficiais de formação de professores, a gestão democrática, a vinculação entre ensino e trabalho produtivo, o trabalho coletivo, entre outros componentes típicos da 
Pedagogia do Movimento, não podem ser colocados em prática dada a forma de estruturação e de organização dessas instituições e dos currículos dos seus cursos. Isso remete à questão dos convênios firmados entre MST, universidades públicas e outras instituições. Ainda que essas iniciativas sejam importantes e também uma forma de disputa em torno do aparelho escolar, elas estáo eivadas de contradiçóes e limitaçóes. Convênios podem apresentar restriçóes no que se refere à aplicação dos elementos constitutivos da Pedagogia do Movimento e dos princípios educativos mencionados, diferentemente de quando os cursos são integralmente concebidos e executados pelo próprio Movimento. Isso reitera a tese defendida pelo MST de que o "educador maior" (MST, 2001, p. 33) dos Sem Terra é o próprio Movimento, em especial pela imersão de seus membros nas suas relaçôes e lutas sociais - a formação dos próprios educadores é uma tarefa não delegável (MST, 1996; 1999; 2001) e deter a hegemonia sobre a formação dos próprios educadores é fundamental, tanto em termos técnico-científicos quanto em termos político-ideológicos. (CALDART, 1997; DAL RI; VIEITEZ, 2008; STEDILE; FERNANDES, 2001)

$\mathrm{Na}$ atualidade, isso se torna ainda mais premente, pois em decorrência do processo contínuo e ascendente de mercantilização, a educação escolar e a pesquisa em ciência e tecnologia assumem papel importante na divisão internacional da produção, do trabalho e do conhecimento. Essa divisão tem relação com o processo de hierarquização vertical entre países e instituiçóes que pesquisam e ensinam, e também com o que pesquisam e ensinam. Esse processo tem impactos negativos na vida da classe trabalhadora, em especial os segmentos de menor poder aquisitivo e de países economicamente periféricos.

Nessa perspectiva, a educação visa principalmente o atendimento às demandas imediatas do sistema produtivo e do mercado de trabalho. Isso faz com que a formação propiciada à ampla maioria dos trabalhadores seja cada vez mais restrita e esvaziada de conhecimentos humanísticos e de outros tipos demandados pela classe, compondo uma educação unilateral. Ao invés disso, o Movimento advoga uma educação integral, omnilateral:

O que poderíamos dizer usando uma expressão mais curta: educação onilateral. A palavra onilateral vem de Marx, que usava a expressão 'desenvolvimento onilateral do ser humano', 
para chamar a atenção de que uma práxis educativa revolucionária deveria dar conta de reintegrar as diversas esferas da vida humana que o modo de produçáo capitalista prima por separar. Ou seja, uma educação onilateral se opõe a uma educação unilateral, que se preocupa só com um lado ou dimensão da pessoa, ou só com um lado de cada vez; só o intelecto, ou só as habilidades manuais, ou só os aspectos morais, ou só os políticos. (MST, 1996, p. 8)

O Movimento (1996, p. 6) reivindica uma educação consistente, abrangente e aberta para o mundo: "Por isso é também característica essencial de nossa educação a preocupação com a abertura de horizontes de nossos/nossas estudantes, de modo que pratiquem aquele velho princípio, também filosófico, de que 'nada do que é humano me pode ser estranho."

A formação de professores não fica imune ao processo de mercantilização e de disputas de variadas ordens. A ênfase dos cursos oficiais tem, em conformidade com a perspectiva hegemônica atual, recaído em aspectos metodológicos e em conteúdos aplicáveis imediatamente no mercado de trabalho, preterindo ou prescindindo da filosofia, da história, da sociologia, da política, entre outros conhecimentos relacionados aos denominados fundamentos da educação.Constatam-se, assim, a necessidade e a pertinência de o MST negar dialeticamente o ensino oficial, pois os elementos constitutivos da sua pedagogia são incompatíveis com o ensino oficial. Quando o MST conquista a hegemonia na escola pública, implanta, não sem contradiçôes ou limitações, o seu projeto político-pedagógico que contém os elementos e princípios proclamados.

Destaque-se que o princípio da formação dos próprios educadores está relacionado com os demais princípios educativos enunciados e que há uma relação necessária entre os diversos aspectos constitutivos do projeto educativo do Movimento. Ressalta-se também a indissociabilidade entre a educação e aspectos das esferas da política, da economia e da cultura da sociedade que a concebe. Ao conceber e executar projeto educacional próprio, inclusive no que se refere à formação de educadores, o MST, assim como outros movimentos, coloca em xeque as pretensas neutralidade e universalidade dos conhecimentos técnico-científicos e dos conhecimentos escolares ${ }^{4}$, tanto em termos de conteúdos quanto em termos de forma. 
Além disso, MST e outros movimentos colocam em tela a histórica demanda de conteúdos socialmente úteis, bem como a histórica polêmica sobre se a educação é um fim em si mesma ou se é um meio para determinados fins. No caso desses movimentos, a educação, sem incorrer em reducionismos, é indissociável de suas necessidades imediatas ou mediatas, em termos técnico-científicos e político-ideológicos. (DAL RI, 2004; 2012; 2013; SILVA, 2014)

\section{Conclusão}

A formação dos próprios educadores é um ponto crucial do projeto educativo do MST. A preocupação com a formação de educadores é central, pois os estudantes, quando formados em outras perspectivas, internalizam valores, ideologias e práticas difíceis de serem abandonadas ou mudadas.

A função de educador é estratégica para qualquer projeto educativo, seja na perspectiva hegemônica seja na contra hegemônica, já que os educadores são, em última análise, os principais responsáveis pela execução do currículo estabelecido. Evidência disso é que, historicamente, essa atividade foi controlada de variadas maneiras, conforme a formação econômicosocial, o momento histórico, a conjuntura e, especialmente, o público a ser atendido pelo educador.

O MST consegue avanços na concepção e na implantação de um projeto próprio de educação, fato que o diferencia de ampla parcela de movimentos de trabalhadores e outros setores que adotam posicionamentos ou referenciais teórico-metodológicos críticos em relação ao sistema do capital ou ao ensino oficial. Não sem contradiçôes e dificuldades de variadas ordens, o Movimento tem registrado importantes avanços, pois consegue sair do âmbito estrito das críticas e das proposiçóes e, conforme as condiçôes objetivas, consegue simultaneamente: a) remediar a precariedade ou inadequação da formação docente oficial em termos de conhecimentos técnico-científicos; b) adequar o ensino tanto em termos técnico-científicos quanto em termos ideológicos ao seu projeto político-educativo.

Como pontuado, a formação dos próprios educadores é, desde o momento histórico da Revolução Industrial, um dos princípios educati- 
vos transcendentes e comuns a alguns dos principais movimentos sociais de trabalhadores, entre eles o MST (DAL RI, 2012). Nas Teses contra Feuerbach, Marx (1999) já afirmava que o próprio educador precisa ser educado. Entretanto, é importante reiterar que, ainda que a formação de educadores seja um ponto fulcral, trata-se apenas de uma faceta de um projeto educativo ou societário. Desse modo, açôes no sentido de intervir nessa faceta ou princípio são necessárias ou mesmo imprescindíveis, porém, isoladamente não são suficientes.

A formação de educadores é um tema recorrente na história da educação e comumente associado, de maneira isolada ou não, à ineficácia da educação escolar, além de não raramente estar presente nas diversas legislações ou reformas relacionadas à educação escolar. Além disso, numa perspectiva mais ampla e mediata, ela está relacionada direta ou indiretamente com concepções de mundo, de educaçáo, de trabalho, entre outras questôes relacionadas às dimensôes materiais e simbólicas da vida.

Considerando-se apontamentos de Vieitez e Dal Ri (2011), podese inferir que os indicativos são de que a educação, por conseguinte, a formação de educadores, tende a continuar ocupando lugar privilegiado na agenda do Estado e de organizaçóes conservadoras, mas também na de movimentos sociais e de organizaçóes que se propóem à realização de transformaçôes sociais estruturais. A tendência é de, por um lado, intensificação e sofisticação dos controles estatais em torno da educação; por outro lado, de organizaçóes de setores das classes trabalhadoras continuarem a conceber ou implementar iniciativas de autoeducação, o que implica disputar com o Estado e outras organizaçôes das classes dominantes a educação das classes trabalhadoras, com vistas à emancipação dessas classes.

No Brasil, desde o momento de fundação do MST até a atualidade, diversas lutas sociais foram - e continuam a ser - travadas por diferentes movimentos, entre eles o MST. Nesse ínterim, diversos direitos foram conquistados na área da educação escolar, tornando, em tese, o acesso à escolarização menos restrito. A Constituição Federal de 1988, bem como leis infraconstitucionais posteriores a ela, garantiram, ao menos formalmente, a ampliação do direito ao acesso, à permanência e à progressão nos estudos. Esses avanços foram decorrência principalmente de históricas lutas de movimentos populares. 
No entanto, especialmente na atualidade, direitos conquistados pelas classes trabalhadoras, como o direito à educação escolar, estão sob ataques cada vez mais intensos. Além do controle ideológico, têm ocorrido restriçôes orçamentárias que tendem a impactar negativamente na qualidade da educação, induzindo, direta ou indiretamente, à privatização da educação pública, inclusive no que se refere à formação de professores, temática que, como apontado, perpassa pautas ou iniciativas de diversos movimentos sociais de trabalhadores desde o século XIX aos dias de hoje, como é o caso do MST.

\section{Notas}

1 Ainda que sejam denominados 'princípios educativos', esclarece-se que os itens trabalhados foram estabelecidos a partir da análise interpretativa inicial efetuada por Dal Ri (2012, 2013). Isso náo significa que esses mesmos itens apareçam nos textos dos movimentos como princípios, embora possam também ser denominados assim por eles. Não significa também que as categorias utilizadas para nomeação de cada princípio constem nos documentos analisados nem mesmo que tais categorias tenham uma compreensão unívoca entre todos os movimentos, não podendo, portanto, serem tomadas nas acepçóes correntes e atuais, dadas principalmente as especificidades político-ideológicas de cada Movimento.

2 Esse retorno deve ocorrer não apenas ao término do curso, mas ainda durante a sua realização, no tempo-comunidade, complementar ao tempo-escola, como preconizado pela Pedagogia da Alternância.

3 Iniciativas implementadas, por força de lei, na Inglaterra do século XIX, para educar as crianças que trabalhavam e os filhos dos trabalhadores.

4 Críticas ao ensino oficial não são exclusividade de movimentos sociais ou de setores contrahegemônicos; setores conservadores também fazem críticas ao ensino oficial, porém, sem visar transformaçôes sociais estruturais. Assim, são críticas fundamentalmente antagônicas, ainda que, em alguns aspectos, possa haver algum ponto de aproximação.

\section{Referências}

BASBAUM, L. Alienação e humanismo. 5 ed. São Paulo: Global, 1982.

BAUER, C. Educação, terra e liberdade: princípios educacionais do MST em perspectiva histórica. São Paulo: Pulsar; Xamã, 2009.

BRASIL. Constituição (1988). Constituição da República Federativa do Brasil.

Disponível em: http://www.stf.jus.br/arquivo/cms/publicacaoLegislacaoAnotada/anexo/ Completo.pdf. Acesso em: 15 abr. 2013. 
Lei $n^{\circ}$ 9.394, de 1996. Estabelece as diretrizes e bases da educação nacional. 1996. Disponível em: http://www.planalto.gov.br/ccivil_03/leis/19394.htm. Acesso em: 7 abr. 2012.

CALDART, R. S. Educação em movimento: formação de educadoras e educadores no MST. Petrópolis: Vozes, 1997.

CAMINI, I. O cotidiano pedagógico de professores e professoras em uma escola de assentamento do MST: limites e desafios. 1998. 165 f. Dissertação (Mestrado em Educaçáo) - Faculdade de Educação, Universidade Federal do Rio Grande do Sul, Porto Alegre.

DAL RI, N. M. Consciencia social, redes y nueva cidadanía: la experiencia educativa del Movimiento de los Trabajadores Rurales Sin Tierra (MST) de Brasil. Rizoma Freireano, Xàtiva, v. 18, p. 1-12, 2015.

- Educação democrática e trabalho associado no contexto político-econômico do Movimento dos Trabalhadores Rurais Sem Terra. 2004. 315 f. Tese (Livre-Docência) - Faculdade de Filosofia e Ciências, Universidade Estadual Paulista, Marília. Disponível em: http://www.athena.biblioteca.unesp.br/exlibris/bd/livre-docencia/2004/ dalri_nm_ld_mar.pdf. Acesso em: 23 jan. 2012.

- Movimentos sociais e educaçáo democrática: antecedentes da pedagogia do trabalho associado. In: ELISALDE, R.; DAL RI, N. M.; AMPUDIA, M.; FALERO, A., PEREYRA, K. (Org.). Movimientos sociales, educación popular y trabajo autogestionado en el Cono Sur. Buenos Aires: Buenos Libros, 2013, v. 1, p. 97-132.

- Movimentos sociais e educação democrática: antecedentes da pedagogia do trabalho associado. Projeto de Pesquisa. Marília, 2012.

; VIEITEZ, C. G. Educação democrática e trabalho associado no Movimento dos Trabalhadores Rurais Sem Terra e nas fábricas de autogestão. São Paulo: Ícone; FAPESP, 2008.

ENGELS, F. A situação da classe trabalhadora na Inglaterra. São Paulo: Boitempo, 2008.

GATTI, B. A. Formação de professores no Brasil: características e problemas. Educ. Soc., Campinas, v. 31, n. 113, p. 1355-1379, out.-dez. 2010. Disponível em http://www. cedes.unicamp.br. Acesso em: 6 jun. 2014.

GOHN, M. G. Movimentos sociais na contemporaneidade. Revista Brasileira de Educação, Rio de Janeiro, v. 16, n. 47, p. 333-361, 2011.

INSTITUTO TÉCNICO DE CAPACITAÇÃO E PESQUISA DA REFORMA AGRÁRIA (ITERRA). Proposta metodológica curso Magistério turma VI - etapa preparatória. Veranópolis, 1997. 
MANACORDA, M. A. História da educação: da antiguidade aos nossos dias. São Paulo: Cortez, 1992.

MARX, K. O capital - crítica da economia política. São Paulo: Difel, 1985. . Teses contra Feuerbach. In: MARX, K; ENGELS, F. A ideologia alemã (I-Feuerbach). 11 ed. São Paulo: Hucitec, 1999, p. 10-14.

MENEZES NETO, A. J. Movimentos sociais e políticos do campo frente a institucionalização: estudo comparado entre o MST e o Zapatismo. In: SEMINÁRIO NACIONAL DE TEORIA MARXISTA, 2014, Uberlândia. Anais..., Uberlândia, 2014.

MOVIMENTO DOS TRABALHADORES RURAIS SEM TERRA (MST). Como fazemos a escola de educação fundamental. Caderno de Educação. MST, s. 1., n. 9, 1999. . MST - Lutas e conquistas. São Paulo: MST, 2010.

. MST Nossos frutos: educação. São Paulo. 2016. Disponível em: http://www. mst.org.br/. Acesso em: 18 jun. 2016. - Pedagogia do Movimento Sem Terra - Acompanhamento às escolas. Boletim da Educação. Porto Alegre, n. 8, jun., 2001. . Princípios da educação no MST. Porto Alegre: MST, 1996. O embrião do MST. Site do MST. São Paulo. 2019. Disponível em: http:// 
TANURI, L. M. História da formação de professores. Revista Brasileira de Educação, São Paulo, n. 14, mai./ago, 2000, p. 61-88. Disponível em: http://www.anped.org.br/ rbe/rbedigital/RBDE14/RBDE14_06_LEONOR_MARIA_TANURI.pdf. Acesso em: 15 fev. 2013.

THOMPSON, E. P. A formação da classe operária inglesa: a força dos trabalhadores. Rio de Janeiro: Paz e Terra, 1987a. v. 3

. A formação da classe operária inglesa: a maldição de Adão. Rio de Janeiro: Paz

e Terra, 1987b. v. 2

TRIVIÑOS, A. N. S. Introdução à pesquisa em ciências sociais: a pesquisa qualitativa em educação. São Paulo: Atlas, 1987.

VICENTINI, P. P.; LUGLI, R. G. História da profissão docente no Brasil: representaçóes em disputa. São Paulo: Cortez, 2009.

VIEITEZ, C. G.; DAL RI, N. M. A educação no movimento social: a luta contra a precarização do ensino público. In: LIMA, F. C. S.; SOUSA, J. U. P.; CARDOZO, M. J. P. B. (Org.). Democratização e Educação Pública: sendas e veredas. São Luís: Edufma, 2011. p. 133-165.

Recebido em Io jun. 2017 / Aprovado em I8 abr. 2019

Para referenciar este texto:

SILVA, C. R.; DAL RI, N. M. Formação dos próprios educadores: um princípio educativo do Movimento dos Trabalhadores Rurais Sem Terra (MST). EccoSRevista Científica, São Paulo, n. 49, p. I-I7, e758I, abr./jun. 2019. Disponível em: https://doi.org/I0.5585/EccoS.n49.758I >. 